\title{
Science Academies' Refresher Course in Experimental Physics
}

\author{
12-27 April 2016 \\ Sponsored by Indian Academy of Sciences, Bengaluru, \\ Indian National Science Academy, New Delhi and \\ The National Academy of Sciences, India, Allahabad \\ In collaboration with Department of Physics, Kashmir University
}

A Refresher Course in Experimental Physics will be held in the Department of Physics, Kashmir University, Srinagar, from April 12 to 27, 2016. This Course aims to familiarize participants with a set of experiments developed as a low cost kit by the Indian Academy of Sciences to cater to the B.Sc. and M.Sc. levels. All experiments verify physical laws and principles and yield reasonably accurate results.

The Course is particularly aimed at teachers teaching at UG/PG level. College/University teachers having at least a Master's degree in Physics are eligible to apply. The UGC has also approved of 2week Refresher Courses of good standing for promotion of teachers, vide notification - F 3-1/2009 dated 30 June 2010. Motivated students of M.Sc./Ph.D. Physics who have a keen interest in Experimental Physics and in teaching physics, may also apply.

Prof. R. Srinivasan who designed these experiments for the benefit of physics teachers and students in Indian universities will be the Course Director.

The Course comprising of lectures, discussions and laboratory sessions will help the participants hone their skills in experimental physics and enable them to introduce the experiments in their respective curricula. The course is mostly a lab work where experiments with accurate results will be carried out under the supervision of trained faculty members

Teachers/Students who wish to participate in this Refresher Course should submit their completed application form (in the prescribed format) by email or by post address (insaku2016@gmail.com), (gulnoor.dar@gmail.com) or Course Coordinator - Refresher Course in Experimental Physics, Department of Physics, Kashmir University, Srinagar, Jammu \& Kashmir 190006 for Application Format please click on the link: http://web-japps.ias.ac.in:8080/Refreshcourse/RCKU.jsp

Last date for the receipt of application filed through proper channel : 20 February 2016.

Selected participants will be intimated through e-mail by 10 March 2016. Selected participants will be provided with local hospitality and round-trip bus/train (III AC) fare by the shortest route. 